\title{
Female Genital Mutilation and Female Genital Cosmetic Surgery
}

\author{
Siren Chen ${ }^{1, *}$ \\ ${ }^{1}$ School of Medicine, Pharmacy and Health, Durham University, Durham, UK \\ *Corresponding author. Email: 20143110@stu.nun.edu.cn
}

\begin{abstract}
There are more than 130 million females worldwide who have been suffered from female genital mutilation. This kind of practice could lead to severe health consequences and became health and human rights issues which gradually spread to western countries because of the migration of population. This article reviews the policies and attitudes of female genital mutilation in the western world. It compares them with female genital cosmetic surgery and finds that even though there are similarities in purpose and operation forms between these two practices, the statement about female genital mutilation and female genital cosmetic surgery differs greatly. For example, female genital surgery was seen as human rights abuse and harmed females' health. On the contrary, female genital cosmetic surgery was considered a safe surgical treatment that could improve their quality of life. It was regarded as self-esteem and a sense of empowerment among the female population. Although it seems that no data reflects that female genital cosmetic surgery might or has already been carried out for cultural or religious reasons, it is strongly publicized as what women do out of their own will and pleasure.
\end{abstract}

\section{Keywords: Female Genital Mutilation, Female Genital Cosmetic Surgery, Medical Ethnics}

\section{INTRODUCTION}

Female genital mutilation is a form of traditional practice that refers to the excision of the female genitalia and normally can lead to severe health consequences [1]. Sometimes this practice is also referred to as female genital cutting (FGC) and female circumcision. Female genital mutilation is predominantly across western, eastern, and north-eastern regions of Africa, parts of the Middle East and Asia, and among migrants from these areas $[2,3]$. However, with the increase of immigrants, female genital mutilation occurs globally in ethnic communities [4]. It is estimated that more than 2 million girls are facing the threat of female genital mutilation every year, and over 130 million African girls and women have already suffered these procedures $[2,3]$. The practice is irreversible and can affect a woman's lifetime [5]. A traditional practitioner gives most female genital mutilation without a sterile environment. The practitioner will use crude instruments such as inserting a twig into the wound to leave a hole for urine and menstrual [6], using acacia thorns as a surgical suture to close the vulva or covering the wound with a mixture of raw egg, herbs and sugar $[5,7]$
There are four types of female genital mutilation, according to the World Health Organization. Type I refers to partial or complete removal of the clitoris and the prepuce. Type II involves the removal of the clitoris with part or all the removal of the labia minora. Type III is to remove part or total of the external genitalia and to suture the wound on both sides of each other suture. Small (or large labia) will be removed, and the clitoris is not necessarily. This kind of practice is the most harmful type, and according to a study in 2008, more than 8 million African women have this experience [8]. According to a survey conducted by UNFPA (United Nations Population Fund) in 2010, 20\% of women who received female genital mutilation were undergoing this type of practice [9]. Type IV is defined as all other procedures which are harmful to female genitalia. This type of practice is rarely seen and mainly involves pricking, piercing, incising or stretching the clitoris and/or surrounding tissues [10].

\section{HEALTH COMPLICATIONS}

Female genital mutilation does harm to the physical and emotional health of women $[11,12]$. Its short-term and follow-up complications are associated with the 
type of female genital mutilation, whether the surgeon has professional training and whether the operation equips with sterilized and disposable equipment and enough antibiotics [13].

Common complications after surgery include wound infection, retention of urine, excessive bleeding and pain [14]. A review of 56 studies in 2015 found that more than $10 \%$ of women had the above complications after female genital mutilation, and the risk of the third type practice is the highest. The report also indicates that the health consequence might be underestimated [15].

Because other complications like sepsis, urinary tract infections, anemia, etc., might not be reported, we can not get exact data about the mortality of women and girls $[12,16,17]$. Though no epidemiological studies can confirm how many patients suffer from infectious diseases such as HIV and hepatitis because of cross-use surgery instruments, a potential risk cannot be denied [12].

\section{REASONS FOR FEMALE GENITAL MUTILATION}

Common reasons for women who practise female genital mutilation include social identity, religion, hygiene and aesthetics, fidelity for marriage and increasing male sexual pleasure [18].

In ethnic communities, people prefer smooth, dry women genital without odour. The natural external sex organ is seen as repulsive, both male and female. Because the vulva is smooth after female genital mutilation, these groups also believe that female genital mutilation contributes to hygiene [19].

For women willing to choose female genital mutilation for their daughters, the UNICEF considers this practice as "self-enforcing social convention". These families think they must comply to avoid the lack of female genital mutilation girls facing exclusion from society [18].

Female genital mutilation first appeared in northeastern Africa and before Islam. Because Islam emphasizes women's chastity and seclusion, so this practice began to link with Islam [20,21]. Quran did not mention female genital mutilation. It is appreciated in the number of hadith (generally considered to record Muhammad's words and deeds). This behavior is considered noble but not necessary, which also suggests practicing more moderately [20]. The Al-Azhar Supreme Council of Islamic Research, held in Cairo in 2007, indicated that there is no basis that female genital mutilation is based on the provisions of the core Islamic law or any other part of the law [22].

\section{POLICIES ON FEMALE GENITAL MUTILATION}

In sub-Saharan, North Africa and the Middle East, many ethnic groups regard female genital mutilation as part of traditional practices [18]. Each region has a different time for female genital mutilation. Some happen just a few days after being born, and some to puberty [21]. As a result of immigrant populations, the practice has extended to European countries, especially in colonial countries like the United Kingdom and France. And also, in the UK, female genital mutilation is one of the successful excuses for refugees to seek asylum [23]. More and more refugees flow from countries where female genital mutilation is a traditional practice, which means the procedure will not disappear gradually.

\subsection{International Reaction}

Up to the year 2013, 33 countries outside Africa and the Middle East had enacted legislation prohibiting female genital mutilation [24]. Immigrants brought female genital mutilation into Australia, New Zealand, Europe, North America, and the Scandinavian Peninsula by immigrants and all of these areas passed legislation to prohibit female genital mutilation [25]. And in 1982, Sweden became the first western country to make restrictions on female genital mutilation [26]. The other five industrialized countries, including Canada, Cyprus, Norway, the UK and the USA, subsequently passed specific laws banning the practice. Countries like France and Germany criminalizing the practice according to the existing penal codes and child protection legislation [27].

\subsection{French Law on Female Genital Mutilation}

The European Parliament said that by March 2009, nearly 500,000 women had had female genital mutilation in Europe [28]. France stands firmly against female genital mutilation while considering the importance of immigrants' assimilation to the French national identity and unity [29]. There are about 30,000 women in France who have undergone female genital mutilation. The public would not intervene in female genital mutilation unless the two girls died of female genital mutilation in 1982 [30].

The provisions of the French criminal law concerning child violence prohibit female genital mutilation. All children born in France must receive a medical examination, including a genitals' inspection, before they are six years of age. If a doctor finds female genital mutilation, he is obliged to report [29]. In 1982, France appeared the first civil lawsuit against female genital mutilation, and in 1993 the first criminal procedure appeared [30]. In 1999, a woman was sentenced to eight years imprisonment for giving female 
genital mutilation to 48 girls [31]. As of 2014, more than 100 parents and two practitioners engaged in more than 40 criminal cases (Female Genital Mutilation) were prosecuted [29].

\subsection{British Law on Female Genital Mutilation}

An important characteristic of British female genital mutilation policy is the reluctance to convict a criminal. Another characteristic is to establish specific clinics for people who have undergone female genital mutilation [32]. A large number of Somali refugees flowed into British in 1987 because of the civil war. The policymakers took into account this reason and focused more on female genital mutilation. By 2011, about 137,000 women and girls living in the England and Wales regions were born in countries where female genital mutilation is traditionally practised. Most of them probably come from Somalia, Kenya, Ethiopia, and Egypt and from Sierra Leone, Tanzania, Ghana, and Nigeria [33].

A difference between the United Kingdom and France is that when a child is under the female genital mutilation threatening, the former will make the Social Services department deal with this situation. In contrast, judicial authorities in France will take the responsibility. There is one more difference between the United Kingdom and France. In 1985, the United Kingdom enacted a ban called the Female Circumcision Prohibition Act to forbid female genital mutilation for girls and women. And the UK was the second European country to pass specialized legislation stopping female genital mutilation. Though the legislation was enacted more than 20 years, no concrete case has been prosecuted thus far [29].

The Act was replaced by the 2003 Female Genital Mutilation Act and the 2005 Prohibition of Female Genital Mutilation in Scotland [34]. The updated law removed some ambiguities, and there is a new policy in place to ensure that young girls from ethnic communities that practice female genital mutilation are not taken out of the UK (e.g. during school holidays) to have female genital mutilation performed on them. Another interesting policy is establishing specific clinics to provide special support and services to women who have experienced female genital mutilation [35].

\section{CONFLICT BETWEEN FEMALE GENITAL MUTILATION AND FEMALE GENITAL COSMETIC SURGERY}

There are exceptions in the legislation against female genital mutilation. The 2003 Female Genital Mutilation Act mentioned that it is legal if the girl or women need surgery for physical or mental health [36]. In 2005 Prohibition of Female Genital Mutilation (Scotland) gives examples of physical or mental health issues. It claims that surgery to remove the cancer tissue on the sexual organs for life-saving and transsexual operation for gender identity is no offence. However, another mental health issue example which Scottish bill mentioned is distress caused by a perception of abnormality. This statement leaves us to consider what kind of operation is necessary and what "abnormality" means. And it remains unclear discourse like "on the facts of the case if a prosecution is brought" [37]. But interestingly, there is no single case prosecution until now, and no reference case exists.

With the increasing attention on female external genital aesthetics, more and more women seeking help from physicians to change the appearance of their external genital surgery [38]. But actually, the information about the "normal" shape and size is mostly from the cosmetic surgery advertisement in magazines or pornography videos, and most of the pictures are "beautified" by software [39].

Many academic research reveals a huge difference in shape, colour, and size of labia among different people. The definitions of "normal" vary from researcher to researcher [40]. Therefore, it is difficult for women and practitioners to have a conception about the "normal" female genital. What's more, this kind of diversity suggests that no normal appearance exists or all shapes or sizes are normal [41]. Our aesthetics, both patients, requiring and practitioners' performance, are affected by time and social trends [42]. In most European countries, a 16-year-old girl can make her own decision on whether to receive this kind of cosmetic surgery. Considering all these complex reasons, it is inappropriate for such a young girl who can consent to a female genital operation [43].

In addition, the female genital operation also happened among minor girls in European countries. It is reported that even some 10-year-old girls undergo female genital cosmetic operations [44]. In 2011, a study data from a London clinic revealed that $15 \%$ of girls subject to female genital cosmetic operation are under the age of 10 and $30 \%$ of patients are between the age of 11 to 15 [45].

There are many similarities between female genital mutilation and female genital cosmetic operations. And some procedures are also exactly the same. For instance, the clitoral hood reduction is a form of excision of the clitoris and labia reduction is also a type of excision [46]. It is only because our attitude towards cosmetic surgery has changed because of media and language usage [47]. As for female genital mutilation, WHO uses partial or total removal to describe the excision, but the surgeons use reduction while describing. The fact is, how can the labia reduction if the practitioner do not remove part of the labia? Moreover, some female genital cosmetic operations are even cruder than part type 4 female genital mutilation practice [14]. 
In the Scottish act, the belief is not taken into account while evaluating women's mental health. Therefore it is illegal if women or girls undergo a female genital operation with the condition of not conforming with traditional community culture [37]

When will social trends or fashion turn to culture or custom? The patients who request surgery are from Africa? For example, it is an offence if a woman with an African accent requests a female genital operation for ritual or cultural reasons, no matter for herself or her daughter. However, it is legal if a woman feels her genital abnormal and wants a labia reduction surgery for cosmetic reasons. Besides, it can bring a heavy interest for the clinic, and the woman has the right and consented to do so [27].

The laws on female genital mutilation and female genital cosmetic surgery suggest discrimination and racialization [47]. One of the reasons for female genital mutilation is to please their partner and white women subject to female genital cosmetic surgery to modify their genital and fit the ideal image. However, for black women, they are considered as being unable to make wise decision and choice also the equality is given by outside $[27,47]$.

\section{CONCLUSION}

In some western liberal democracies, female genital mutilation was defined as a crime explicitly. However, in the meantime, a body-modification practice termed female genital cosmetic surgery has gained great popularity within these countries. A new body modification procedure called "cosmetic surgery" has recently gained great popularity in these countries. Unlike the strict legal supervision of female genital mutilation procedures in the west, 1.7 million female genital cosmetic surgery were performed in the United States alone in 2008. There are similarities in these two procedures and share the same underpinning ideas: the physical harm they created and the attempt to be accepted by their original community. So, all of these are giving rise to another question, shall we regulate female genital cosmetic surgery? Or shall we popularize female genital mutilation medicalization?

\section{REFERENCES}

[1] Klein, Elliot, et al. "Female genital mutilation: health consequences and complications - a short literature review." Obstetrics and gynecology international 2018 (2018).

[2] United Nations Children's Fund, and Geeta Rao Gupta. "Female genital mutilation/cutting: a statistical overview and exploration of the dynamics of change." Reproductive Health Matters (2013): 184-190.
[3] Whitehorn, James, Oyedeji Ayonrinde, and Samantha Maingay. "Female genital mutilation: cultural and psychological implications." Sexual and Relationship Therapy 17.2 (2002): 161-170.

[4] Van Vossole, A., et al. "Female genital mutilation in the European Union and Croatia." (2013).

[5] World Health Organization, and UNICEF. "Female genital mutilation: a joint WHO/UNICEF/UNFPA statement." Female genital mutilation: a joint WHO/UNICEF/UNFPA statement. 1997. 20-20.

[6] Abdulcadir, Jasmine, et al. "Care of women with female genital mutilation/cutting." Swiss medical weekly 141.0102 (2011).

[7] Momoh, Comfort. "Female genital mutilation." Current Opinion in Obstetrics and Gynecology 16.6 (2004): 477-480.

[8] Yoder, Stanley, and Shane Khan. Numbers of women circumcised in Africa: The production of a total. United States Agency for International Development, 2008.

[9] Comfort, Momoh. "Female genital mutilation." The Social Context of Birth. Routledge, 2017. 129-144.

[10] Newland, Lynda. "Female circumcision: Muslim identities and zero tolerance policies in rural West Java." Women's studies international forum. Vol. 29. No. 4. Pergamon, 2006.

[11] Berg, Rigmor C., et al. "Effects of female genital cutting on physical health outcomes: a systematic review and meta-analysis." BMJ open 4.11 (2014): e006316.

[12] Reisel, Dan, and Sarah M. Creighton. "Long term health consequences of Female Genital Mutilation (FGM)." Maturitas 80.1 (2015): 48-51.

[13] Kimani, Samuel, and Bettina Shell-Duncan. "Medicalized female genital mutilation/cutting: contentious practices and persistent debates." Current sexual health reports 10.1 (2018): 25-34.

[14] Paakkanen, E. Katariina. "Entitled, empowered or victims-an analysis of discourses on male and female circumcision, genital mutilation/cutting and genital cosmetic surgery." The International Journal of Human Rights 23.9 (2019): 1494-1520.

[15] Berg, Rigmor C., and Vigdis Underland. "Immediate health consequences of female genital mutilation/cutting (FGM/C)." (2018).

[16] Iavazzo, Christos, Thalia A. Sardi, and Ioannis D. Gkegkes. "Female genital mutilation and infections: a systematic review of the clinical evidence." Archives of gynecology and obstetrics 287.6 (2013): 1137-1149. 
[17] Morris, Kelly. "Feature: Issues on female genital mutilation/cutting - progress and parallels." The Lancet 368 (2006): S64-S67.

[18] Young, Janine, et al. "Diagnosis, management, and treatment of female genital mutilation or cutting in girls." Pediatrics 146.2 (2020).

[19] Gruenbaum, Ellen. "Socio-cultural dynamics of female genital cutting: Research findings, gaps, and directions." Culture, health \& sexuality 7.5 (2005): 429-441.

[20] Mackie, Gerry. "Ending footbinding and infibulation: A convention account." American sociological review (1996): 999-1017.

[21] Rouzi, Abdulrahim A. "Facts and controversies on female genital mutilation and Islam." The European Journal of Contraception \& Reproductive Health Care 18.1 (2013): 10-14.

[22] El-Gibaly, Omaima, et al. "The decline of female circumcision in Egypt: evidence and interpretation." Social science \& medicine 54.2 (2002): 205-220.

[23] Powell, Richard A., et al. "Female genital mutilation, asylum seekers and refugees: the need for an integrated UK policy agenda." Forced migration review 14 (2002): 35.

[24] United Nations Children's Fund, and Geeta Rao Gupta. "Female genital mutilation/cutting: a statistical overview and exploration of the dynamics of change." Reproductive Health Matters (2013): 184-190.

[25] Australia. Attorney-General's Department. Review of Australia's Female Genital Mutilation Legal Framework. Attorney General's Department, 2013.

[26] Essén, Birgitta, and Sara Johnsdotter. "Female genital mutilation in the West: traditional circumcision versus genital cosmetic surgery." Acta obstetricia et gynecologica Scandinavica 83.7 (2004): 611-613.

[27] Kelly, Brenda, and Charles Foster. "Should female genital cosmetic surgery and genital piercing be regarded ethically and legally as female genital mutilation?." BJOG: An International Journal of Obstetrics \& Gynaecology 119.4 (2012): 389-392.

[28] Yoder, P. Stanley, Shanxiao Wang, and Elise Johansen. "Estimates of female genital mutilation/cutting in 27 African countries and Yemen." Studies in family planning 44.2 (2013): 189-204.

[29] Kool, Renée SB, and Sohail Wahedi. "Criminal enforcement in the area of female genital mutilation in France, England and the Netherlands: a comparative law perspective." International Law Research 3.1 (2014).

[30] Gallard, Colette. "Female genital mutilation in France." Bmj 310.6994 (1995): 1592-1593.

[31] Gollaher, David L. "Circumcision: a history of the world's most controversial surgery." (2000).

[32] Leye, Els, et al. "Debating medicalization of Female Genital Mutilation/Cutting (FGM/C): learning from (policy) experiences across countries." Reproductive health 16.1 (2019): 1-10.

[33] Pazdor, Margery Rose. Female genital mutilation in France and the UK: the role of non-governmental organizations in policy formation. Diss. University of British Columbia, 2009.

[34] Parekh, Bhikhu C. The future of multi-ethnic Britain: Report of the commission on the future of multi-ethnic Britain. Profile Books, 2000.

[35] Sales, Rosemary. "Britain and Britishness: Place, belonging and exclusion." Muslims in Britain. Routledge, 2012. 42-61.

[36] Johansen, R. Elise B., et al. "Health sector involvement in the management of female genital mutilation/cutting in 30 countries." BMC health services research 18.1 (2018): 1-13.

[37] Female Genital Mutilation (Scotland) Act 2005. [online] Available at: $<$ http://www.legislation.gov.uk/asp/2005/8/contents $>$

[38] Krivenko, Ekaterina Yahyaoui. "Rethinking human rights and culture through female genital surgeries." Hum. Rts. Q. 37 (2015): 107.

[39] Tiefer, Leonore. "Female genital cosmetic surgery: Freakish or inevitable? Analysis from medical marketing, bioethics, and feminist theory." Feminism \& Psychology 18.4 (2008): 466-479.

[40] Laan, Ellen, et al. "Young women's genital self-image and effects of exposure to pictures of natural vulvas." Journal of psychosomatic obstetrics \& gynecology 38.4 (2017): 249-255.

[41] Lloyd, Jillian, et al. "Female genital appearance: 'normality' unfolds." BJOG: An International Journal of Obstetrics \& Gynaecology 112.5 (2005): 643-646.

[42] Paarlberg, K. Marieke, and Philomeen Th M. Weijenborg. "Request for operative reduction of the labia minora; a proposal for a practical guideline for gynecologists." Journal of Psychosomatic Obstetrics \& Gynecology 29.4 (2008): 230-234. 
[43] Goodman, Michael P., et al. "Evaluation of body image and sexual satisfaction in women undergoing female genital plastic/cosmetic surgery." Aesthetic surgery journal 36.9 (2016): 1048-1057.

[44] Jothilakshmi, P. K., et al. "Labial reduction in adolescent population - a case series study." Journal of pediatric and adolescent gynecology 22.1 (2009): 53-55.

[45] Crouch, N. S., et al. "Clinical characteristics of well women seeking labial reduction surgery: a prospective study." BJOG: An International Journal of Obstetrics \& Gynaecology 119.4 (2012): 504-505.

[46] Levine, Stephen B. "Fashions in genital fashion: Where is the line for physicians? Commentary on Veale and Daniels (2011)." Archives of sexual behavior 41.3 (2012): 735-736.

[47] Bennett, Theodore. "Beauty' and' the beast': Analogising between cosmetic surgery and female genital mutilation." Flinders Law Journal 14.1 (2012): 49-68. 